of ovarian tumours are lucid and in spite of many references to other sources, steer a clearly understood path through the maze that traps so many postgraduate students.

The section on gynaecological operations could only have been written by men who are as good technical masters as the authors are; and who have been teaching surgery for years.

Use has been made of the drawings of Victor Bonney, and since both authors were pupils of the great Bonney, the operative technique described derives from his, but there are many modern advances added.

The book is detailed in the extreme. It was a pleasure for instance to find more than one page devoted to true hydatid tumours, when the reviewer had unexpectedly found one at laparotomy. Yet the book is certainly not encumbered with unnecessary reading material.

The reproduction of the diagrams is, in the main, excellent, although perhaps a little more pruning of some of the old illustrations might have been carried out because they do add to the price; yet the work is remarkable value, and is probably now a 'must' for the M.R.C.O.G.

But why did the publishers produce such a dull dust jacket for such a brilliant book ?

E.E.P.

\section{CLINICAL ASPECTS OF THE AUTONOMIC NERVOUS SYSTEM}

By L. A. Gillilan, Ph.D., M.D. Pp. xii +316 , with 42 illustrations. London: J. \& A. Churchill Ltd. 1955. 45s.

Professor Gillilan has given us a most interesting account of the anatomy of the autonomic nervous system. He has demonstrated a number of important consequences arising from the anatomy of this part of the nervous system. The presentation and printing are excellent and it is easy to look up the neuro-anatomy of any particular region. A wide range of references is given.

It is surprising perhaps that some rather fundamental work has been omitted from the text, such as Lewis's work on referred pain, and the work of Guttmann and Whitteridge on afferent pathways from the bladder, or the work of Harris and others on the hypothalamic control of some pituitary mechanisms. One finds, too, some feeling of confusion in the use of the works 'sympathetic' and 'para-sympathetic,' although the author does himself draw attention to some paradoxes involved in the ordinary use of these terms. There are instances in which perhaps the explanations given of clinical phenomena are a little over-simplified. The view is expressed that there is a vaso-constrictor sympathetic inflow and a vaso-dilator para-sympathetic inflow, and this view of the control of the peripheral blood vessels is, if correctly interpreted by the reviewer, most unorthodox.

This book will be of considerable interest to most medical men and in particular to those who have special interest in the autonomic nervous system. $\stackrel{\mathbb{D}}{\mathcal{Q}}$

K.E.C.

\section{MAN IN A COLD ENVIRONMENT}

By Alan C. Burton, Ph.D. and Otto G. Edholm, 을 M.B., B.S. Pp. xiv +273 , with 75 illustrations. London: Edward Arnold Ltd. 1955. 3os."

Over the past quarter of a century a great deal of knowledge has been accumulating on the physio- logical responses of man to his environment. Little. of this information has so far reached the standard $\vec{A}$ textbooks and most of that which has done so is $\vec{\rho}$ made up of rather dogmatic half-truths. The time was therefore ripe for a more detailed account of some aspects of body temperature regulation in man. The authors of this book have set themselves the $\omega$ difficult task of reviewing a very wide field of work. They have rightly used a considerable space in $y^{-}$ reviewing and describing the physical principles $\omega$ which must be common knowledge to anyone who? aspires to intelligent research in temperature $\delta$ regulation. Besides this, the physics of the designo of insulated clothing are discussed and this section? is presented in easily readable form. The remainderc of the book, which deals with the physiological responses to cold, is well written and contains a good $\overrightarrow{.}$ selection from the available literature. There age also within the book some very thought-provokikg philosophical discussions. The authors have dowe a good job in selecting the salient features from vast mass of literature and this book, because of the way in which the principles underlying temperature regulating mechanisms are discussed, should form part of the armament of anyone interested in body temperature regulation.

K.E.C.

\section{NEUROLOGY}

By S. A. KINNIER Wilson, M.A., M.D., D.Sc., $\frac{\partial}{3}$ F.R.C.P. Edited by A. Ninian BruCE, F.R.C.P., D.Sc., M.D., F.R.S. Second edition. Three Vols. Pp. xii, viii and viii $+2060+99$, with 279 illustrations. London: Butterworth \& Co., Ltd. 양 1954. £10 ros. the set or $£ 3$ ros. per vol.

This work, which covers over 2,000 pages, is in three volumes. The second edition includes a new $D$ chapter on aphasia, apraxia and agnosia, and the chapter on neurosyphilis has been modified. The N general character of the first edition has been undisturbed.

This is in many ways a remarkable book. The N historical field it covers is enormous; indeed, the $\omega$ text bristles with so many references as to become in places hard to follow. The style of writing is that of an age which has passed from medical $\mathbb{\infty}$ literature and the pages are larded with an abundance? of latin tags. The approach to the subject, too, is $\square$ somewhat dated, belonging to an era when toxins in ${ }^{\circ}$

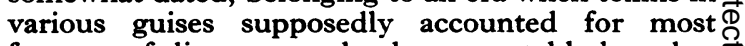
features of disease not clearly accountable by other $\mathbb{D}$ 
mechanisms. An attempt has been made to incorporate recent advances in neurology, but the book is not fully up to date; cerebral angiography (with thorotrast) is mentioned in the section on cerebral tumours and the latest reference to this procedure appears to be one dated 1935 .

Proof correction has been imperfect; thus on page 52 'penicillin is sensitive to the pneumococcus' and on page 70 'rigour' is written for 'rigor.'

The book is entirely lacking in a modern physiological approach to neurology, but it will have a place on the medical bookshelf as an invaluable source of historical commentary and reference.

R.R.H.L.

\section{THE CASUALTY DEPARTMENT}

By T. G. Lowden, M.A., B.M., B.Ch., F.R.C.S. Pp. viii +278 , with 170 illustrations, 20 in colour. Edinburgh: E. \& S. Livingstone Ltd. 1955. 37s. 6d.

Mr. Lowden's object has been to produce a book which, by drawing on experience gained during a seven-years' study in a casualty department, will provide guidance for casualty officers. Nowadays, when the work of casualty departments has assumed far greater importance than formerly, such a book is clearly needed, and to a great extent Mr. Lowden has succeeded in his aim.

In the first 98 pages, septic conditions-always a major problem of casualty work-are admirably treated, and the place of antibiotics in treatment is clearly defined. Soft-tissue injuries, both closed and open, are next considered, and in a valuable chapter are described those simple methods of skin grafting which are suitable for use in a casualty department. Principles for the treatment of burns are laid down, and in the last sections such important matters as the organization and the legal aspects of casualty work are considered.

It is, perhaps, unfortunate that in the particular region whose casualty department $\mathrm{Mr}$. Lowden has studied, fracture treatment has been segregated to a separate accident hospital. This has meant that the treatment of even minor fractures forms no part of the present work, and this gap certainly detracts from the general usefulness of the book. Most casualty officers will have to undertake the primary treatment of fractures, and Mr. Lowden would be well advised to add to future editions a chapter dealing with the general principles and possible hazards of fracture work.

In the section dealing with injuries of the peripheral nerves, Mr. Lowden might perhaps be criticized for not taking a firmer stand against primary suture. Few casualty departments are staffed or equipped sufficiently well to permit of primary nerve suture, and general experience suggests that, even when staff are highly trained and facilities adequate, secondary suture gives the best results. It is perhaps too, a valid criticism of the chapter on 'Anaesthetics' that Mr. Lowden does not go very fully into the technique of regional anaesthesia by brachial plexus block-a technique $\frac{2}{2}$ which has proved very satisfactory in Continental clinics and whose advantages have led to an increase of its use in England.

These criticisms apart, Mr. Lowden is to be con- $\overrightarrow{\vec{c}}$ gratulated on producing a book which will certainly be useful to all those engaged in casualty work. It is to be hoped that he will in later editions somewhat $\frac{\sigma}{\overline{0}}$ enlarge the scope of the work so as to make it of $\frac{\mathcal{D}}{\sigma}$ even greater general use.

\section{PHYSIOLOGY IN DISEASES OF THE HEART $\vec{\circ}$ AND LUNGS}

By M. D. Altuschule. Revised edition. Pp. $x v+554$. London: Geoffrey Cumberlege. 흐 Harvard University Press. 1954. 6os.

That the immense and painstaking labour of collection and consideration that evidently went $\vec{\omega}$ into the making of this book was prompted by the $\mathrm{G}$ demands of senior medical undergraduates at $i \omega$ Harvard Medical School, is a tribute to the spirit of enquiry which must prevail among them.

The author collates and comments upon a mass of relevant literature divided and subdivided under the main heads of chronic cardiac decompensation, $\overrightarrow{\vec{c}}$ acute pulmonary edema, angina pectoris, cardiac $\subseteq$ arrhythmias, pericarditis, congenital and acquired $<$ cardiac defects, pulmonary fibrosis, chronic pu\& $\overrightarrow{0}$ monary emphysema, bronchial asthma, pleur or affusion, pneumothorax and pneumonia. The pror. fessed aim of the author is first, to present the facts and then to drape theory upon them; he is less concerned with the concept elaborated by a worker than by consideration of the data which he assembles. In fact, as he states in the Preface, his $\mathbb{D}$ conclusions sometimes differ from or oppose those of the worker whose findings he presents.

Success in this aim is achieved at the expense of comfortable reading. Continuity of text is frequently broken by lists of names. The focus of attention shifts rapidly from one aspect to another $\bar{\partial}$ of the subject under discussion. Emphasis waxes and wanes. It is like a series of lantern slides, each $\bar{\sigma}$ depicting a different view of the same scene, each seen too briefly for full appreciation. Many ideas $\delta$ are presented but synthesis is not attempted.

The bibliography is enormous and a most valuable source of information for those with special $\frac{}{\supset}$ interests in cardiovascular and pulmonary physi- $\frac{D}{2}$ ology and disease. More than half the pages are taken up by titled bibliographic references, arranged $\mathrm{N}$ alphabetically, by author's name, at the end of each or sub-section. The whole work is carefully indexed. $\mathrm{O}$

H.K.

\section{MEDICINE IN ITS HUMAN SETTING}

By A. E. Clark-Kennedy, M.D., F.R.C.P. Pp. 276 illustrated. London: Faber and Faber, Ltd. $\stackrel{\oplus}{+}$ I 954. I3s. 6d.

Written for all and any who have an interest in medicine and rather more than a slight acquaintance with its concepts, Dr. Clark-Kennedy's book must 